\title{
EVALUATING EFFICACY OF CONCEPTUAL SEDIMENT BARRIER MATRIX TOWARDS ECOSYSTEM RESTORATION ATTRIBUTES
}

\author{
Shekhar Salunke ${ }^{1}$, Chavan B.L. ${ }^{2}$ \\ ${ }^{1}$ Dept of Environmental Science, Solapur University, Solapur, MS, India \\ ${ }^{2}$ Dept of Environmental Science, Dr. B.A.M. University, Aurangabad, MS, India \\ Ph;9422501866, email:spr_salunke@bsnl.in
}

\begin{abstract}
The rationale behind the study was to estimate effectiveness of Eichhornia leaf filter sleeves as a sediment barrier matrix towards soil erosion and sediment control practice to curtail adverse impacts associated with sedimentation at the lake waters. The study had an objective to implement the development to fit the site under study to stabilize exposed soils as soon as practicable. The prime objective was to estimate the sediment captured by the sleeve to control and manage on-site by protecting the areas and retain sediment on-site. Primarily Eichhornia leaf filter sleeves (Sun dried premature Eichhornia leaf fills) crammed in an IS 16008 (2012)- tubular mesh sleeve as a linear land based treatment filter to primarily study the efficacy of filtration ability of sediments and soluble pollutants a further contemplation. It is found that besides sediments some of the pollutants can be trapped in sediments downstream. The efficacy of the model was analyzed to be successful in preventing sediment inflows at the lake waters. Effectively percent reduction of sand $89 \%$, TSS $68 \%$, silt $56 \%$, turbidity $51 \%$, and clay by $18 \%$ was recorded. This describes the effectual exploitation of the notorious weed Eichhornia biomass sleeve towards reducing sediments and turbidity of runoff waters entering the lake waters enhancing the ecological status of the lakes. The studies portray the application of the Eichhornia sleeve in high reduction in total suspended solids and sand.
\end{abstract}

Keywords: Conceptual Model, Sediment Barrier, Aquatic Ecosystem, Restoration.

$* * *$

\section{INTRODUCTION}

The study area, Lake Sambhaji is located at $3.6 \mathrm{~km}$, approximately at the city Solapur of Maharashtra State, India. It is a natural lake with an area of 25.35 ha. The lake is located geographically, between Latitude: $\mathrm{N} 17^{\circ} 38^{\prime} 55.61$ \& Longitude: E $75^{\circ} 54^{\prime} 13.9$, an altitude of $491.94 \mathrm{~m} \mathrm{msl}$. The water from the reservoir is being used for irrigation for forestry and fisheries. The lake suffers a huge sedimentation problems and thereby causing problems of the soil erosion, sedimentation and surface water turbidity. Soil erosion is a major land management issue due to stringent regulations on water quality and efforts to reduce the impact of various activities on sedimentation. Surface erosion is the movement of individual soil particles by a force, either by uniform removal of material from the soil surface (sheet erosion) or by concentrated removal of material in the downslope direction (rill erosion) [1 Foster 1982]. Erosion occurs due to wind and water primarily. Due to anthropogenic activity when the land is been disturbed there is an increase in the rate of erosion. The combination of precipitation, steep slopes, and erosive soils cause sheet and gully erosion. The surface runoff ultimately produces eroding channels which is known as rill erosion. Rills further broaden and result in gully erosion. Further when the eroded material is discharged into streams, ponds or lakes it results in the degradation of the water quality and poses a serious threat to the aquatic habitats. Besides sediments the water quality is also degraded by chemical fertilizers, pesticides and pathogenic microorganisms through the eroded particulates. Erosion is reduced by all material on or above the soil surface, such as naturally occurring vegetation, surface litter, rocks, and synthetic materials such as erosion mats, mulches, and other barriers that reduce the impact of the applied forces [2 McNabb, David H.; Swanson, Frederick J. 1990]. The effectiveness of a strategy depends principally on the researcher's capability to choose appropriate controls that address the exclusive distinctiveness and problems posed by a specific site. The success of the strategy relies on appropriate implementation of the erosion and sediment control strategy. There is a need to conserve natural features, drainage patterns, and vegetation; minimizing impervious surfaces; slowing down and/or filtering runoff. Therefore erosion and sediment control management plan must be integrated. An attempt was made through a pilot project to control sedimentation at lakes through a conceptual model preventing sediment flow into the lake waters with simulated runoff.

\section{MATERIALS AND METHODS}

Preventing soil erosion and sedimentation reduces impacts from disturbances and aids the overall accomplishment and safeguarding of water quality standards. The sedimentation control through the use of management practices to reduce sedimentation coupled with the non-structural practices is needful to diminish the impact on water resources. Data inventory through aerial photo (fig.3) of the site under investigation including the adjacent areas was used to recognize significant site distinctiveness, to develop the plan to control sedimentation along with additional as features of adjacent areas. Contour elevations pertaining to the slope 
and at intervals of one to five feet were studied through a topographic map and LISS-III imageries (Fig. 4,5,6,7), of the site under investigation. The study also considered the existing patterns of drainage with both; upstream and downstream areas adjacent to the proposed site. The vegetation cover on the site was also studied that included herbs, shrubs and trees with a special reference of the grassy areas and the exposed surface of the soil. To determine the method of erosion control technique intended to be employed on the site the predictable runoff volumes and velocities were computed. The carrying capacity of the streams on the site receiving runoff was surveyed to establish the mode of sedimentation control before the water leaving the site. The length of slope and steepness was studied where the steeper and longer slope that tends to increase the erosion potential due to runoff flow was preferred for the implementation of the sleeve project. Adjoining areas with analogous steepness were clustered. The gradients of slope were categorized into the ranges of soil erodibility as: $0 \%$ to $3 \%$ having low erosion potential, $3 \%-8 \%$ having medium erosion potential. $0 \%$ to $3 \%$ was recorded to be about 280 feet in the study area where the erosion potential was found to be more serious, however the slope length at certain study area exceed the $3 \%$ to $8 \%$ beyond 148 feet. Hence primarily the sleeve application was chosen to be installed at the range of $0-3 \%$ slope of length 280 feet. The study area indicated existence of natural drainage patterns, consisting of depressions and overland flow, which aided to locate the possible critical areas where concentration of water occurred. The ground cover did not indicate any grass ground cover portraying the possibility of erosion. Thus the sleeve installation was considered at this site as it was assumed to reduce the erosion potential. The velocity of flowing water was found to be inadequate towards the transport of sediment as it came across the barriers towards the movement of sediments. Larger particles were found first to be deposited during reduced flow velocities as against the finer sediments which did not settle.

The design and layout was prepared and installed following the guidelines provided for the design and installation following [3] Maryland Standards and Specifications for Soil Erosion and Sediment Control, 2011, (Fig.8), [4] (UNEP- Caribbean Environment Programme); CEP Technical Report No. 32, 1994 \& [5] Iowa Construction Site Erosion Control Manual. Iowa Department of Natural Resources (IDNR), 2006. For the sleeve preparation, primarily premature Eichhornia leaf filter (Sun dried Eichhornia leaves ) filled in a IS 16008 (2012)- tubular mesh sleeve as a linear land based treatment filter to study the efficacy of filtration ability of sediments (primarily) (and soluble pollutants;- further contemplation). The sleeve made up of a U.V. stabilized shade net of 150 GSM of high strength) Net specifications- (Commercially available U.V. stabilized shade net of 150 GSM of high strength, manufactured from HDPE granules, of Type III, having shading factor of 90 percent., with mass $140, \mathrm{~g} / \mathrm{m}^{2}$, satisfying retention of breaking strength $85 \%$ percent of original actual value of the fabric after UV exposure, 1.70 $\mathrm{mm}$ width of the tape used in the fabric, and linear density of the tape 40 Tex (400 Denier). Width after ravelling $=50$ $\mathrm{mm}$, Gauge length $=200 \mathrm{~mm}$., With 290 average breaking strength of shade net fabric (Ravelled strip method), both wrap way and weft way, were placed on contours, perpendicular to rill or gully water flow channels, five feet i.e. about 1.5 meters ahead of the slope toe permitting sediment deposition, accumulation of runoff and maximum storage of sediments on the prepared ground surface. Eichhornia biomass filter sleeves were installed at $8 \% / 12 \% / 18 \% /$ and $24 "$ as the slope identified was between $2 \%$ to $5 \%$. These were placed across the channel in ' $\mathrm{V}$ ' formation in a straight line. The sleeves were found to physically filter coarse and fine sediments and opined to chemically filter some soluble pollutants that are to be analyzed, (a contemplated study). Biomass quality studies revealed $\mathrm{pH} 7.2$, Soluble salt concentration in terms of electrical conductivity $4 \mathrm{mmhos} / \mathrm{cm}$, Moisture content percent, wet weight basis 52, Organic matter content percent, dry weight basis 48 , agreeable with the specifics stated by the U.S. Environmental Protection Agency (2006). The size of the percent particles passing through the sleeve mesh, was recorded on dry weight basis. Rainfall simulation was conducted in the pilot project of $3.1 \mathrm{inch} /$ hour for 1 hour in a plot size of 3' wide and 16' long. Sediments were found to be trapped in varying pore spaces and sizes.

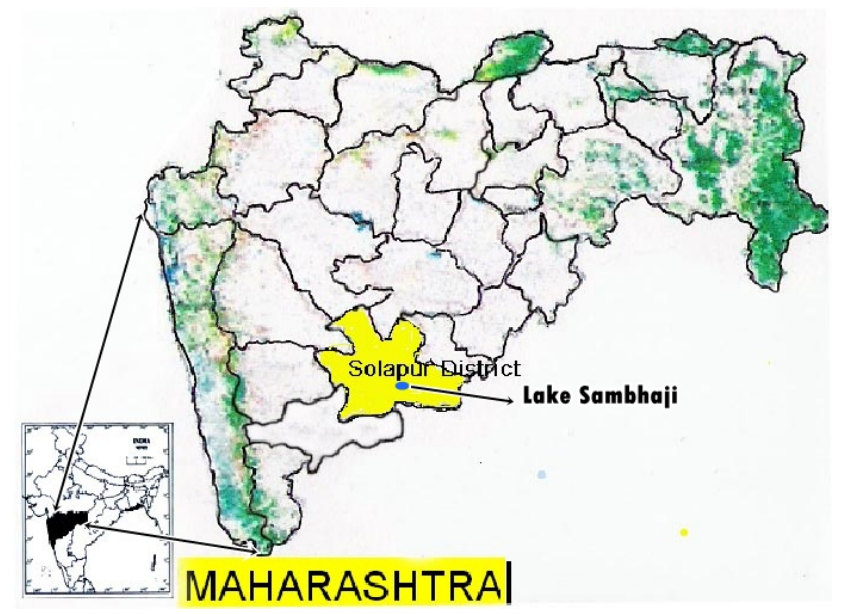

Fig 1. Map of Maharashtra State

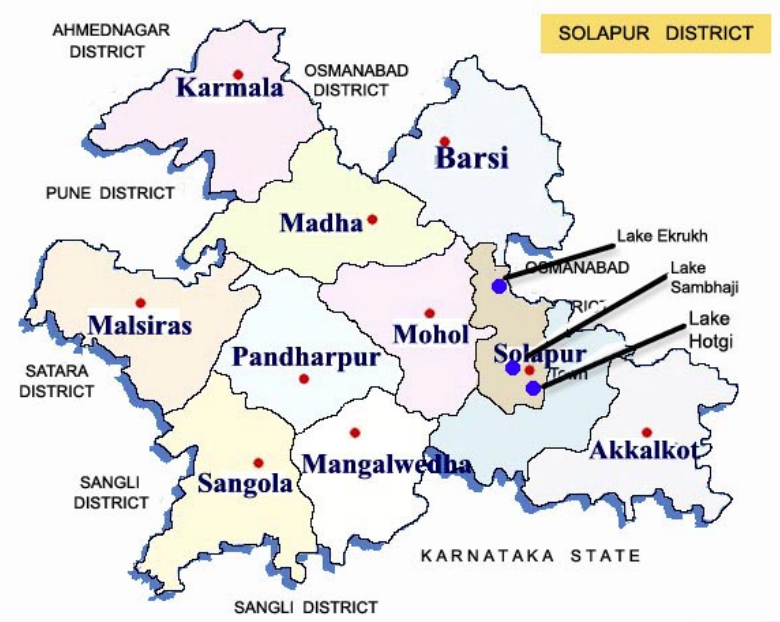

Fig 2. Map of Solapur District Showing Lake Location 


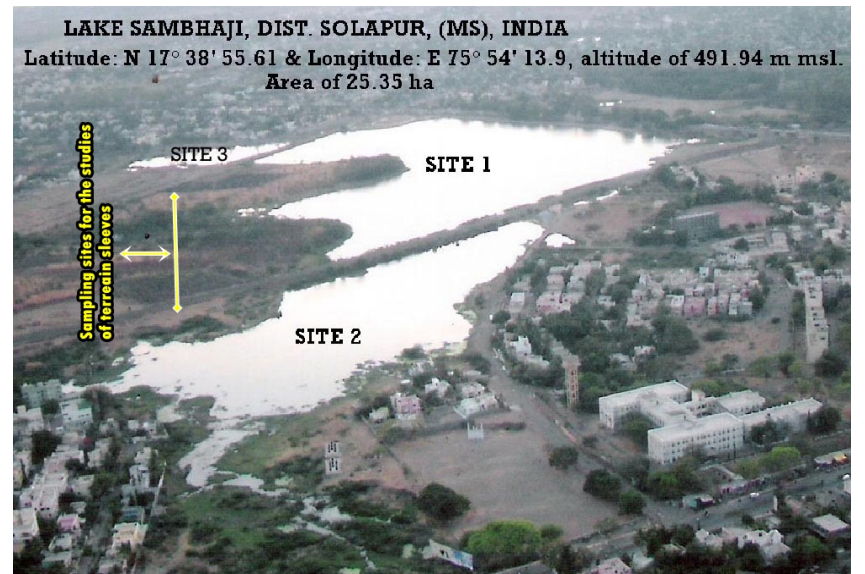

Fig 3. Aerial photograph of the site- Lake Sambhaji

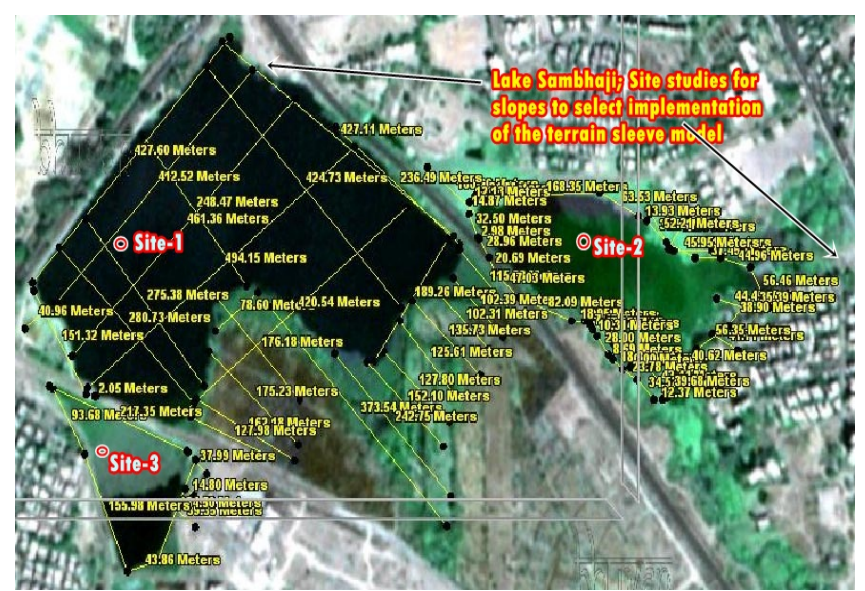

Fig 4. Site studies of Lake Sambhaji through LISS III imagery

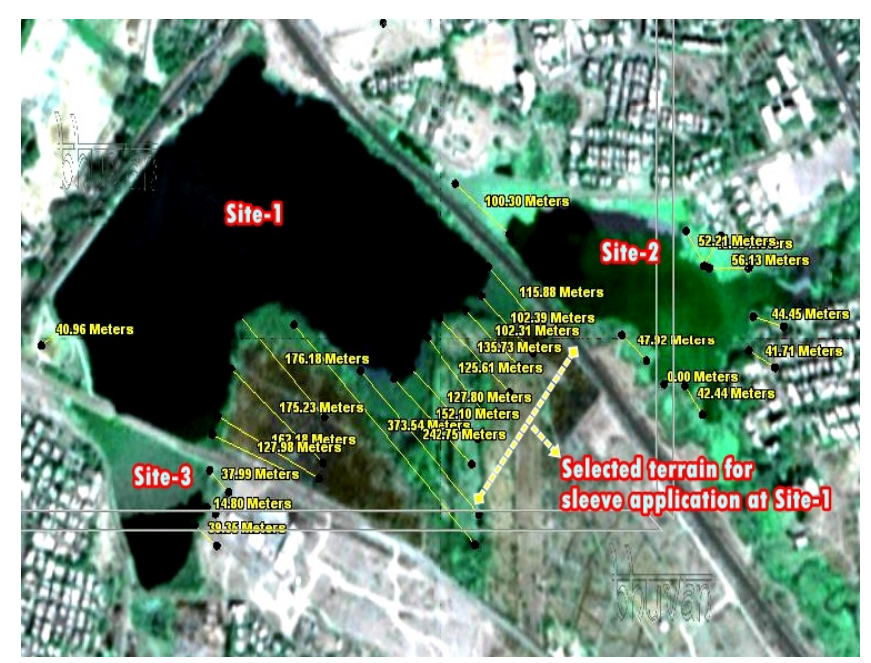

Fig 5. Defining possible sampling sites for the studies of terrain sleeve application

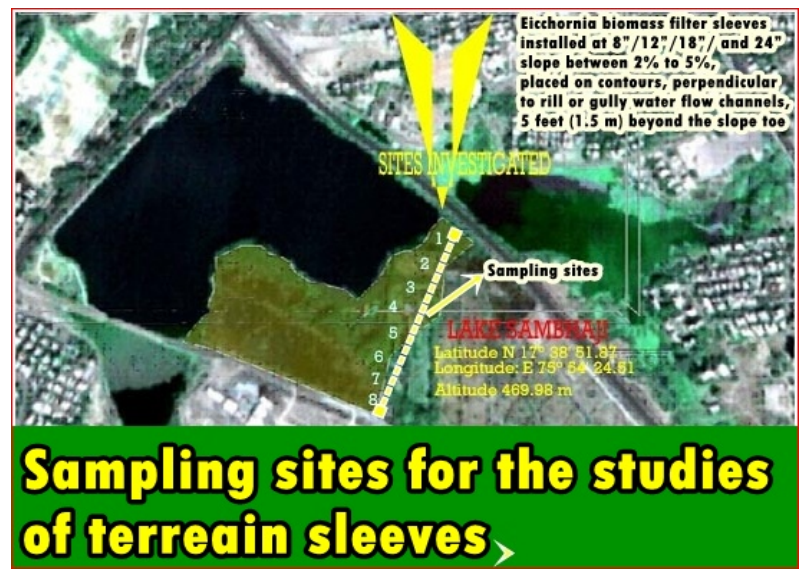

Fig 6. Selection of sampling sites for the studies of terrain sleeve application

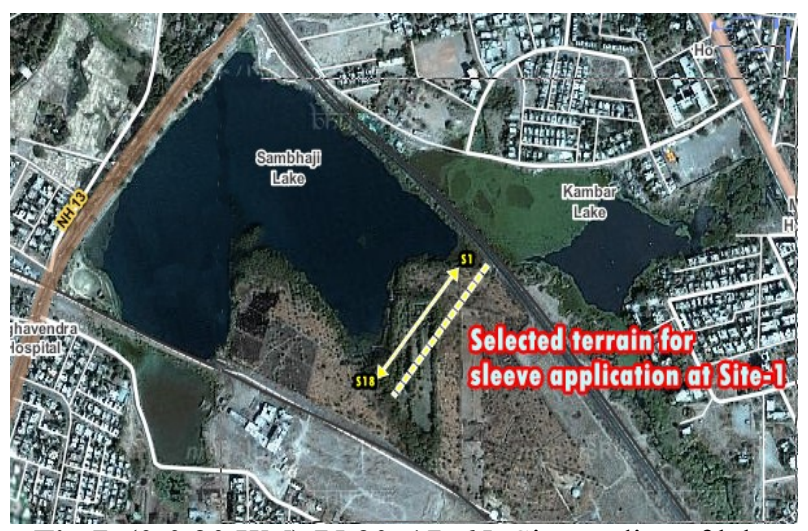

Fig 7. (0-0.20 KM) 75.90, 17..65, Site studies of lake Sambhaji (Geo-platform ISRO)

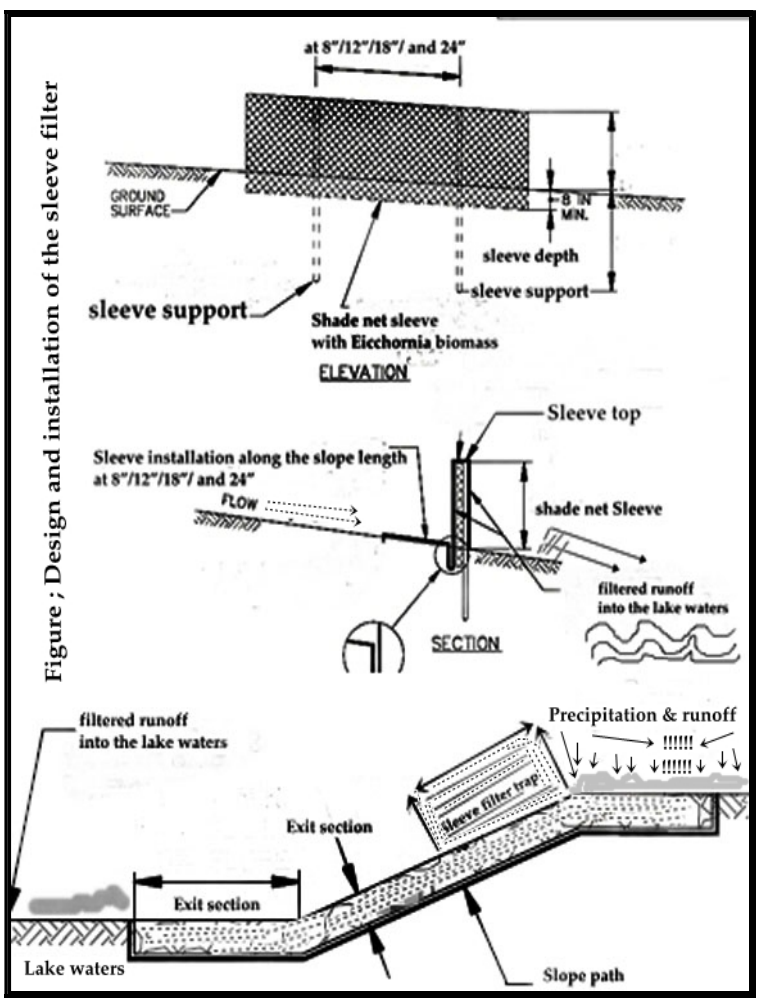

Figure 8. Design and installation of the sleeve filter. (Following Maryland Standards and Specifications for Soil Erosion and Sediment Control, 2011) 


\section{RESULTS AND DISCUSSIONS}

The attempt was to minimize potential for erosion towards sediment control practice by conveying inlet waters in a non-erosive approach down the slope. The sleeve was applied to trap sediment for relatively small drainage area in a pilot project, confining and settling the sediment loaded runoff from the drainage area. The soil was found to be coarse textured soil. As such the soil portrays low- holding capacity, nutrient holding capacity, lower compaction potential, fast warming and drainage potential. This projects the high runoff potential and sedimentation capability in the lake water. The studies conclude with the excellent results (Fig. $14 \& 15$ ) of reduction in the sediments as mentioned in table 2 . The decisive factors were analyzed were percent reduction of sand $89 \%$, TSS $68 \%$, silt $56 \%$, turbidity $51 \%$, and clay by $18 \%$. This depicts the effective use of Eichhornia biomass sleeve towards reducing sediments and turbidity of runoff waters entering the lake waters enhancing the ecological status of the lakes. The studies portray the application of the Eichhornia sleeve in high reduction in total suspended solids and sand. However the clogging rate and the effectiveness after clogging is yet to be studied.

Table; 1 Slope studies of the selected site

\begin{tabular}{|l|l|l|}
\hline \multicolumn{1}{|c|}{$\begin{array}{c}\text { SITE } \\
\text { SAMPLED }\end{array}$} & \multicolumn{1}{c|}{$\begin{array}{c}\text { SLOPE } \\
\text { DEGREES }\end{array}$} & \multicolumn{1}{c|}{ SLOPE } \\
\hline S1 & 1.44 & 2.51 \\
\hline S2 & 1.49 & 2.60 \\
\hline S3 & 1.50 & 2.61 \\
\hline S4 & 1.21 & 2.11 \\
\hline S5 & 1.16 & 2.02 \\
\hline S6 & 0.99 & 1.72 \\
\hline S7 & 0.83 & 1.44 \\
\hline S8 & 0.85 & 1.48 \\
\hline S8 & 0.94 & 1.64 \\
\hline S10 & 1.34 & 2.33 \\
\hline S11 & 1.76 & 3.07 \\
\hline S12 & 1.72 & 3.00 \\
\hline S13 & 1.58 & 2.75 \\
\hline S14 & 0.50 & 0.87 \\
\hline S15 & 0.38 & 0.66 \\
\hline S16 & 2.05 & 3.57 \\
\hline S17 & 1.58 & 2.75 \\
\hline S18 & 0.36 & 0.62 \\
\hline & sampled site at site 1 \\
\hline
\end{tabular}

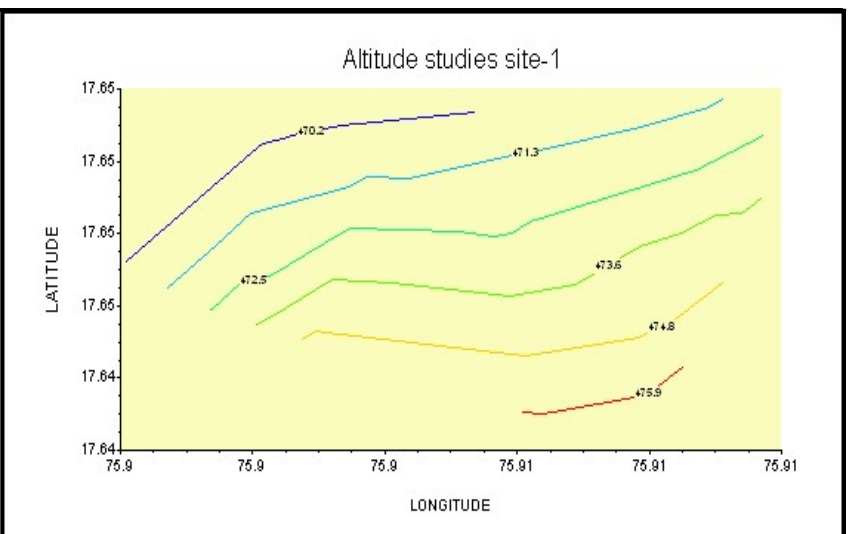

Fig 9. Altitude studies of the proposed site (Terra Plot)

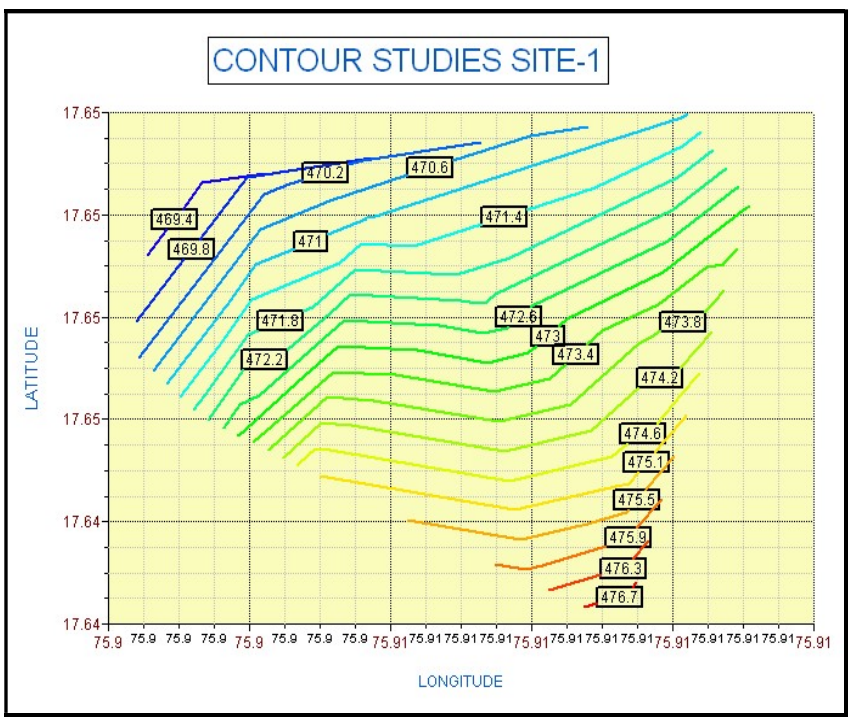

Fig 10. Contour studies of the proposed site (Terra Plot)

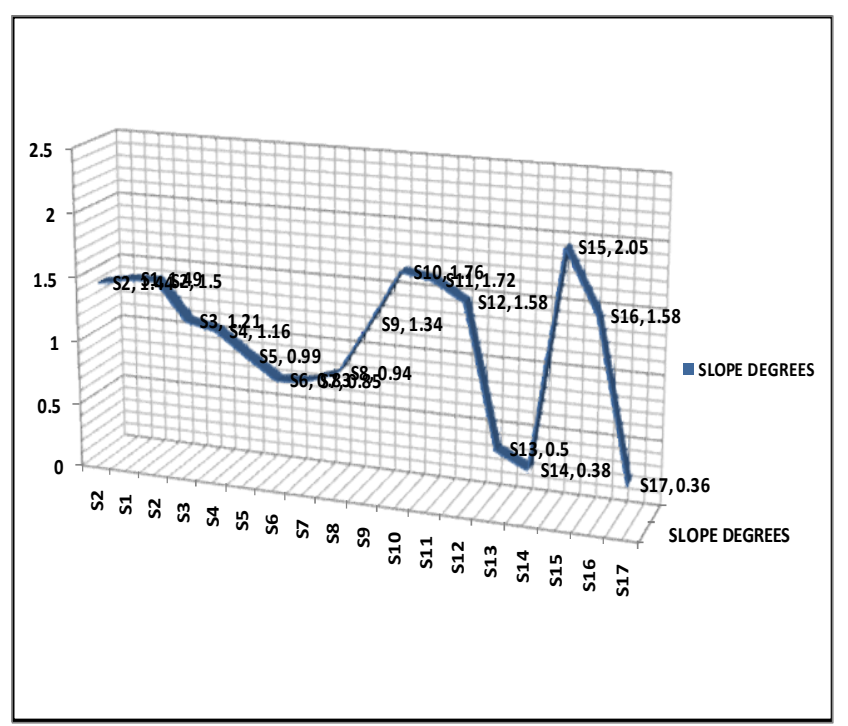

Fig 11. Slope studies of the site (Terra Plot) 


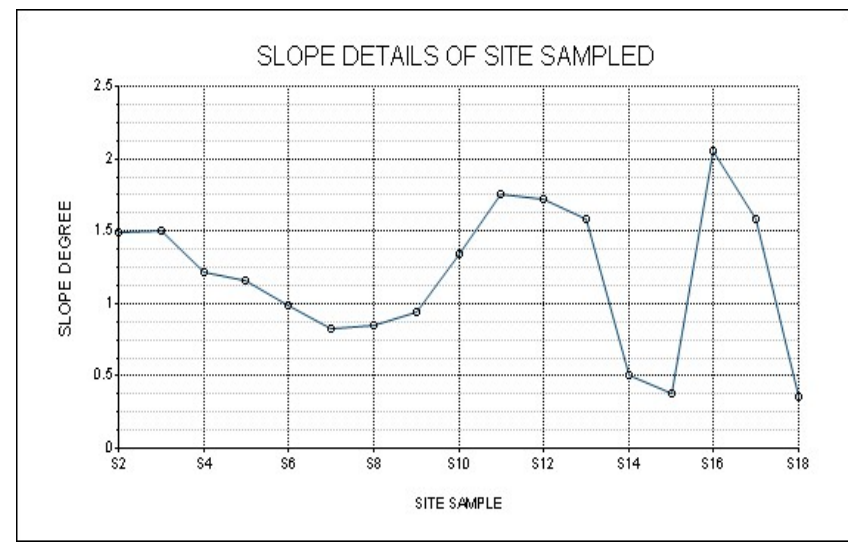

Fig 12. Slope analysis of the site (Terra Plot)

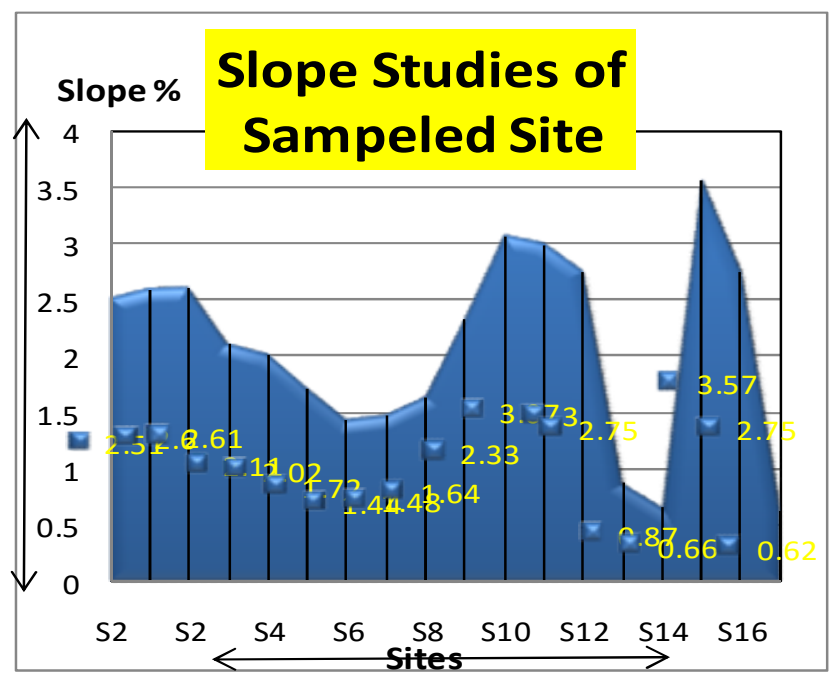

Fig 13. Estimation of the terrain slopes of the site

Table 2. Impact of sleeve application

\begin{tabular}{|l|c|}
\hline \multicolumn{1}{|c|}{$\begin{array}{c}\text { Decisive } \\
\text { factor }\end{array}$} & $\begin{array}{c}\% \\
\text { Reduction }\end{array}$ \\
\hline TSS & 68 \\
\hline Turbidity & 51 \\
\hline Silt & 56 \\
\hline Sand & 89 \\
\hline Clay & 18 \\
\hline
\end{tabular}

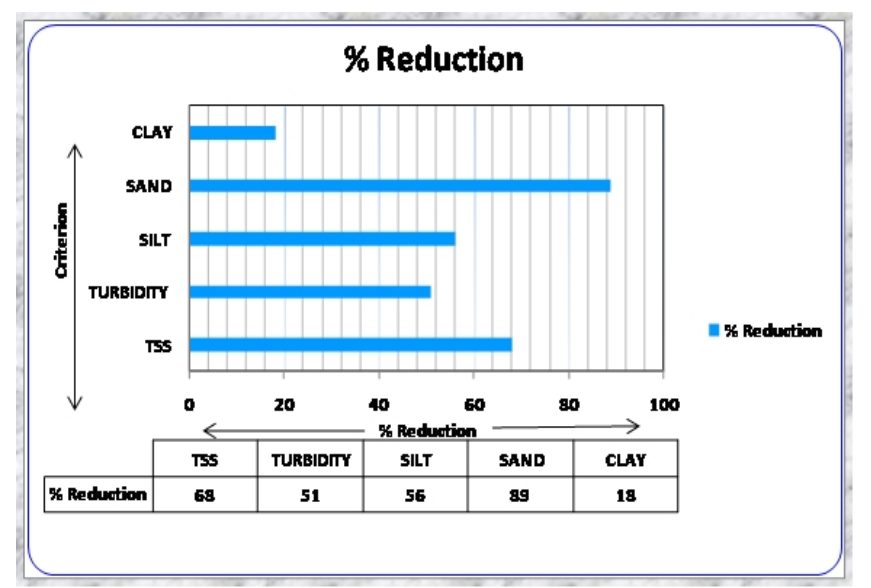

Fig 14. Impact of application of filter sleeve in terms of $\%$ reduction of pollutants.

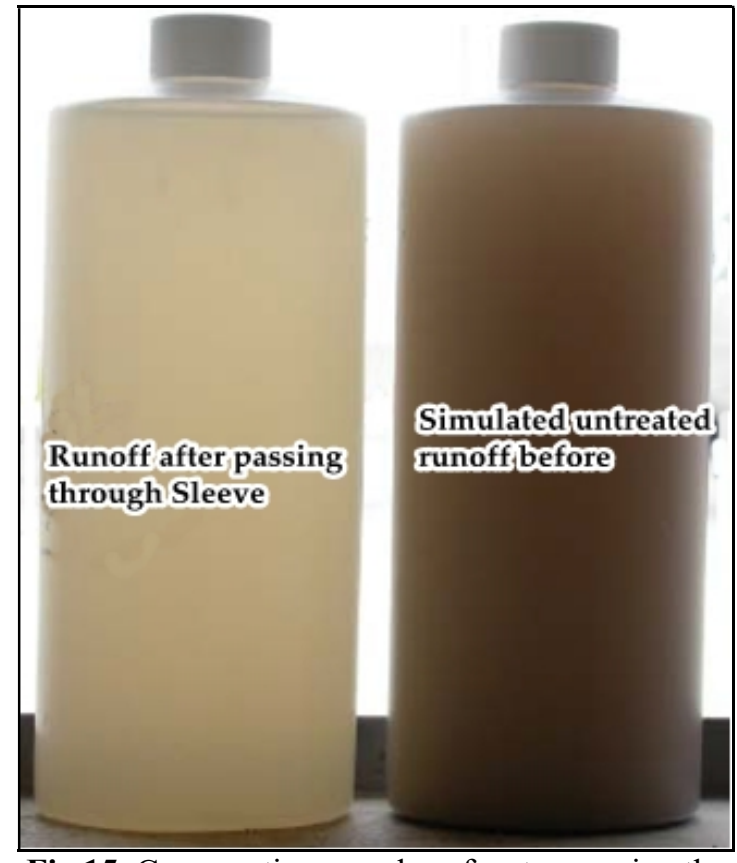

Fig 15. Comparative samples of water proving the effectiveness of the sleeve

\section{CONCLUSIONS}

The Eichhornia filter sleeve can be effectively used towards; perimeter sediment control, to reduce soil erosion in rills and gullies. It can also be used as an inlet protection guard. For the diminution of suspended solids and turbidity in slope interruption practice it can be employed to diminish the velocities of sheet flows and prevent gully or rill erosion. Collectively it can be successfully used to reduce soil erosion and habitat destruction to protect sensitive wetlands, water bodies, wildlife habitat, and ecosystems. The use of the filter sleeves help in escalating the soil ecosystem permanence and services. The investigations portray the use of weed for land based filtration and pollutant removal application and as an ecosystem restoration attribute. The method is advocated to be advantageous as there is no need of trenching and hence there is disturbance caused to the habitat including the flora or soil, disturbances. The sleeves can be installed on soils that are rigorously compressed or also on the paved surfaces. The filter sleeve made from locally available materials employing the use of notorious weed Eichhornia that helps wise utilization of the weed to reduce the flow quantity and velocity of the water dividing the slope length in petite subdivisions. The sleeve application advocates utilization for protection of inlets, for erosion control practices along the slopes, for the diversion of slopes or for the perimeter control. However the functional longevity of the sleeve design is projected to about 6-8 months. However this can be applicable during the rainy season which lasts for a very short time, since the study area is arid.

\section{LIMITATIONS}

Although the filter sleeve was found to be fairly adaptable, this management practice has certain limitations. If the quality of the compost of the biomass used is not sustained, 
particularly for the particle size distribution and also the biological stability, the efficacy possibly will severely be diminished. For inappropriately prepared land surface, the Eichhornia biomass filter sleeve shall not serve the designated purpose. This condition may allow untreated inlet flow. Eichhornia biomass filter sleeves cannot be placed in perennial streams sine clogging may interrupt the filteration capability. Mechanical movement over the filter sleeves may diminish the field performance and capacity of the sleeves. The clogging rate and the effectiveness of the sleeve after clogging are yet to be studied.

\section{ACKNOWLEDGEMENT}

We express our gratitude to Dr. E. Elango Scientist, NRSC, Dept. of Space, Govt. of India, Hyderabad, A.P. for providing the requisite imageries \& long-term consultation for the successful completion of project. We further extend our appreciation to the Principal, Walchand College of Arts \& Science, Dist. Solapur, Maharashtra State, India, for his keen interest and continuous guidance for the research activities. We also thank Mr. Rajesh Moholkar, D.Jain Gurukul College, Dist. Solapur, Maharashtra State, India, for aiding the design and installation programme. With sincere expectations that the studies shall be a continued effort our project to extend advanced scientific studies to enrich, improve and focus on priority the sites for detailed inventories in the proposed subsequent phase.

\section{REFERENCES}

[1] Foster, G. R. 1982. Modeling the erosion process. In: Haan, C. T.; Johnson, H. P.; Brakensiek, D. L., eds. Hydrologic modeling of small watersheds. St. Joseph, MI: American Society of Agricultural Engineers: chapter 8 .

[2] David H. McNabb and Frederick J. Swanson ; Effects of Fire on Soil Erosion; http://andrewsforest.oregonstate.edu/pubs/pdf/pub1055. pdf

[3] Guidelines for sediment control practices in the insular Caribbean- - Sandra Elaine Stevenson, (UNEPCaribbean Environment Programme); CEP Technical Report No. 32, 1994.

[4] Iowa Construction Site Erosion Control Manual, Iowa Department of Natural Resources (IDNR), 2006.

[5] Maryland Standards and Specifications for Soil Erosion and Sediment Control, 2011.

[6] U.S. Environmental Protection Agency. 2006. National Pollutant Discharge Elimination System, Phase II. Compost Filter Socks: Construction Site Stormwater Runoff Control. National Menu of Best Management Practices for Construction Sites. (http://cfpub.epa.gov/npdes/stormwater/menuofbmps/in dex.cfm? action=factsheet_results\&view $=$ specific \&bmp 120)..

\section{BIOGRAPHIES}

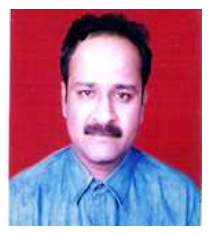

Research Student, Department of Environmental Sciences, School of Earth Sciences, Solapur University, Solapur, (MS), India. \& Lecturer at Walchand College of Arts \& Science, Solapur (MS), India \& Secretary at; Centre for Environment, Solapur, (MS), India, E-mail address:-spr_salunke@bsnl.in

The Author is currently engaged in the EnvironmentalProtection, Training, Education \& research activities

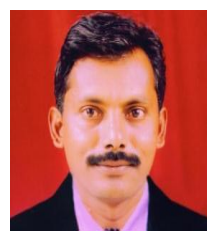

Professor Department of Environmental Sciences, Dr. Babasaheb Ambedkar Marathwada University, Aurangabad, MS, India.

E-mail: chavandrbl@rediffmail.com Speciality Climate Change \& Disaster Management, Environmental Pollution and control technologies, Environmental Legislation. Biostatistics and environmental modeling. 